\title{
(6) OPEN ACCESS \\ Appealing to the crowd: ethical justifications in Canadian medical crowdfunding campaigns
}

\author{
Jeremy Snyder, ${ }^{1}$ Valorie A Crooks, ${ }^{2}$ Annalise Mathers, ${ }^{1}$ Peter Chow-White ${ }^{3}$
}

\begin{abstract}
'Faculty of Health Sciences, Simon Fraser University, Burnaby, British Columbia, Canada

${ }^{2}$ Department of Geography, Simon Fraser University, Burnaby, British Columbia, Canada

${ }^{3}$ School of Communication, Simon Fraser University, Burnaby, British Columbia, Canada
\end{abstract}

\section{Correspondence to}

Dr Jeremy Snyder, Simon Fraser University, Blusson Hall 10516, 8888 University Drive, Burnaby, British Columbia, Canada V5A 156; Jcs12@sfu.ca

Received 8 September 2016 Revised 25 November 2016 Accepted 9 January 2017

Published Online First

30 January 2017

\begin{abstract}
Medical crowdfunding is growing in terms of the number of active campaigns, amount of funding raised and public visibility. Little is known about how campaigners appeal to potential donors outside of anecdotal evidence collected in news reports on specific medical crowdfunding campaigns. This paper offers a first step towards addressing this knowledge gap by examining medical crowdfunding campaigns for Canadian recipients. Using 80 medical crowdfunding campaigns for Canadian recipients, we analyse how Canadians justify to others that they ought to contribute to funding their health needs. We find the justifications campaigners tend to fall into three themes: personal connections, depth of need and giving back. We further discuss how these appeals can understood in terms of ethical justifications for giving and how these justifications should be assessed in light of the academic literature on ethical concerns raised by medical crowdfunding.
\end{abstract}

Medical crowdfunding is the practice of using websites to raise money from donors to pay for medical care or expenses related to medical care. Many different social networking companies facilitate medical crowdfunding through their websites, including popular sites such as GoFundMe and YouCaring. Those setting up and administering crowdfunding campaigns can be the intended recipient of the donations or a friend or family member administering the campaign on the recipient's behalf. These campaigns appeal both to friends and family members of the campaign's recipient and to strangers who may not know the recipient. This practice is growing in terms of the number of active campaigns, amount of funding raised and public visibility. ${ }^{12}$ One of the leading medical crowdfunding sites, GoFundMe, illustrates this growth: in 2011, GoFundMe hosted 8000 medical crowdfunding campaigns raising US $\$ 1.6$ million in donations and by 2014 raised US $\$ 150$ million in 600000 campaigns. $^{3}$

Medical crowdfunding has the potential to generate substantial benefits for recipients, allowing them to access needed medical treatment, avoid debt from receiving medical care and have family members spend additional time with ill loved ones. However, this practice has also been associated with a range of ethical concerns. Medical crowdfunding can be used to take advantage of donors through fraudulent campaigns. ${ }^{2}$ The recipients of these donations risk negative impacts as well, including loss of privacy given pressure to communicate extensive details about their health status in the campaign. ${ }^{4}$ Other ethical concerns are more systemic in nature, including worries about encouraging the distribution of health resources through private donations rather than public entitlements as well as unfairness and inefficiency in which individuals and health needs are rewarded through crowdfunding. Furthermore, medical crowdfunding tends to ignore the underlying causes of insufficient resources to meet medical needs in favour of portraying these needs as bad luck. ${ }^{5}$

Very little research has been conducted to explore why individuals use medical crowdfunding, what barriers they face when conducting these campaigns and how campaigns are distributed in terms of the location of recipients and their underlying health needs. ${ }^{5}$ Research has shown that crowdfunded lending to entrepreneurs is more likely when campaigners present narratives of themselves as trustworthy and successful. ${ }^{6}$ Those donating to charitable crowdfunding campaigns are motivated both by altruism and benefits to self-esteem. ${ }^{7}$ However, little is known about how campaigners for medical crowdfunding appeal to potential donors outside of anecdotal evidence collected in news reports on specific medical crowdfunding campaigns. This paper offers a first step towards addressing this knowledge gap by examining 80 medical crowdfunding campaigns for Canadian recipients in order to explore how Canadians justify to others that they ought to contribute to funding their health needs. We explore how these appeals can be framed around ethical justifications for giving and how these justifications should be assessed in light of the academic literature on ethical concerns raised by medical crowdfunding.

\section{METHODS}

We identified and gathered 80 medical crowdfunding campaigns for Canadian recipients for review during March and April 2016. We collected the 20 most recent such campaigns from each of four commonly used crowdfunding websites: FundRazr. com (F), Generosity.com (G), GoFundMe.com (GFM) and YouCaring.com (Y). They were the four most popular crowdfunding websites measured by their web traffic in Canada (as measured by Alexa. com), allowed campaigns for Canadian recipients, and clearly displayed the location of the recipient in order to allow distinctions between Canadian and non-Canadian campaigns.

The researchers extracted all text from the campaigns and stored the data in a shared spreadsheet. 
We reviewed independently the textual content of 40 campaigns, each having been read in detail by two authors, noting identifying patterns and outliers among the campaigns. We then met to come to consensus on dominant themes across the campaigns, which is consistent with a thematic approach to qualitative data analysis. ${ }^{8}$ We all agree that campaigns generally made an attempt to justify giving by the potential donor, and identified three dominant themes that contribute to understanding the scope of such justification. The lead author manually extracted content related to each theme and together we contrasted what we learned about these themes against the existing crowdfunding literature-an important step in thematic analysis-to identify the potential for a novel contribution and points for discussion.

\section{FINDINGS}

We found that requests for help focused on monetary gifts and included campaigners asking that readers send their 'thoughts and prayers', spread word of the campaign and in a few cases practice prevention of the disease or donate blood. The campaigns were for medical needs related to a range of illnesses or treatments as well as acute situations such as injuries following vehicle collisions, but in nearly half of all cases referenced a cancer diagnosis. Other common illnesses included kidney disease, neurological disease and Lyme disease. In the remainder of this section, we examine the findings pertaining to campaign donation justification, organising them around three analytic themes: (1) personal connections between the recipient and potential donor; (2) the recipient's need for help and the good that can be done by the donation and (3) giving back to recipients who had previously given to their communities. To enhance the reliability of our interpretation, we have included direct quotes throughout as well as unique identifiers for each that begin with an indication of the host website.

\section{Personal connections}

In many cases, the reviewed campaigns either assumed that only friends and family members of the campaign's recipient would be engaging with the content or made special appeals to friends and families. Often campaigns appealed to friends and families in the tone of an open letter to these groups. In others, the assumption that friends and families were a special audience for these appeals was stated directly, as in a campaign that began: "I'm guessing that if you're reading this, you know and love Steve" (Y23). Readers in other cases were asked to share the campaign with those who knew the recipient. Many of these campaigns assumed that the reader was already familiar with the recipient's medical needs and so used the campaign largely as a means of organising friends and families in their giving activities.

Personal relationships with those in need were often framed explicitly as creating an obligation to donate. As one campaigner put it: "I truly believe that when we have someone we care about in need, we should gather around them as one big family and help as much as possible" (GFM20). Another put the requirement to give in the form of an imperative: "[the home team of her friends, colleagues and family] must be there for as long as she needs us" (F6). In one case, the campaigner recognised that a request for financial help could place a strain on friendships, and stressed the importance of these relationships over his need: "Dear friends and family who are reading this, please know that I sincerely hope you feel under no obligation whatsoever, and that thoughts, prayers, kindness, insights, and friendship are as deeply important to me as financial help" (GFM16). For this campaigner, the love and support of friends and families could be expressed in non-financial means, the importance of which was stressed. This idea was echoed in other campaigns, where non-financial support such as prayers were asked of loved ones and it was even expressed that 'family and community support is essential to healing process' (Y22).

\section{Depth of need}

Many campaigns sought to motivate donors' giving through a detailed description of the recipient's medical need. Often, they sought to give a history of the recipient's medical treatment to date, in part to introduce the reader to the process by which the need has arisen. These descriptions can be graphic: 'So far Celine has been in the OR [operating room] for surgery 3 times, each time having more and more of her leg tissue removed, making the wound larger and more severe' (GFM9). Similarly, a young woman is described as having experienced 'a broken shoulder, broken ribs, a punctured lung and several broken vertebrae, partially severing her spine' from a car accident (Y8). The long-term, chronic nature of illness was also described in some cases, as with one who stated that: "Ever since I can remember I've been living in pain" (Y16). Another campaigner attributed her medical need to barriers faced in the Canadian healthcare system: "not one MD [medical doctor] has been able to help me. One even told me to seek a psychologist. With respect to the diagnosis and care of Lyme Disease, the Canadian healthcare system has been, for me, a nightmare" (GFM6).

Campaigners also stressed the impact of medical need on others. Young persons, and especially children, were framed as being particularly in need of help. In one case, a young child's life-threatening illness was movingly described through the child crying 'Mommy Daddy save me' (G10). Children were often described as deserving more years of life: 'She is only 15 years old and has a long happy life to live' (G9). The tone of these messages was that suffering was especially unacceptable in children, as when: 'no three year old should have to know the inside of a hospital as well as Ryan does, because no parent should have to know how to answer the kind of questions that Ryan's parents are having to answer' (G1). Even adults were flagged as suffering too early in their lives, as in the case of one recipient who is 'only 32 and was in worse shape than most people several times his age' (Y13). Parents of young children were similarly identified as having greater need of help, with the impacts of parents' loss of income due to illness or absence from their family stressed. In one case, fundraising for an ill parent was justified in part by the recipient having children with their own medical crises. In this case, 'The loss of an income, no matter how temporary, will be devastating to this hardworking, caring family' (F1).

Campaigns often pivoted between detailed characterisations of recipients' ill health and how financial assistance could alleviate that need. Many campaigners described crowdfunding as a last resort. Their campaigns had the practical benefit of helping reduce the recipient's illness and/or improving health and wellbeing: "I need your support now as I fight for my life. No donation is too small; and is very much appreciated" (G1 2). Several campaigns detailed existing support from friends and families but stressed the need of additional help: 'Many people have asked how they can help. At this point, financial assistance is what's needed' (Y9). Similarly, "My family and I are here to support her but there is no doubt she requires financial assistance in order to deal with the foreseeable financial commitments" (F4). In other cases, this potential benefit was stated as a simple fact, where readers are invited 'to join us in helping $\mathrm{Al}$ and his family' (Y12). In these ways, the good that could be done via these donations was taken self-evidently to justify donating. 


\section{Giving back}

Many campaigns emphasised the selfless characteristics of recipients and the good works that they have engaged in the past. Recipients were described as being 'compassionate, loving, giving and one of the most caring women on this planet' (GFM2), as having 'a huge heart' (GFM20) and 'giving heart' (Y5), 'unselfish, kind, caring and giving' (F7), a 'man who puts others first' (F1) and 'literally one of those people who would give you the shirt off his back' (F10). A typical campaign described the activities that the recipients engaged in great detail: 'loading (almost too) many children into their adventure van, selflessly shuttling them home and on play dates. They are front and centre at all of our events, volunteering by sharing their time, knowledge and creations. "Come on over!" is their most common phrase, as they have been a social hub of our class and community' (G8). The good works described in these campaigns included both those targeting friends, family and community members, and also those directed at strangers and persons in need regardless of personal connections.

In some cases, the past efforts of the recipients on behalf of others were used as a rationale for the reader to contribute to the crowdfunding campaign. Because of the 'inspiring' work that she/he had done for others, a campaign noted the recipient 'deserves us to all rally together to help her fight' (GFM2). Similarly, another recipient 'would stop at nothing to help a friend or person in need' and therefore, 'Now it is our turn to help' (Y12). Other campaigns described the recipient as running up a line of credit of good works that justified help now that the campaigner, later in life, was in a position of need. For example, one recipient was described as a 'person who was always there for others when needed, and now its come to a time in his life where he needs us' (GFM12). Similarly, donations were justified as a reward for past help: 'Let us show them that generosity of spirit is rewarded in this crazy world' (G8). Parents' good works could justify help for their children as well, as in the case of one campaign where the parents of a child with cancer had been 'supporting cancer research selflessly' (G1). The reluctance of one generous recipient to accept help, always preferring to give help to others, was presented in another campaign as creating a 'chance to show our appreciation and gratitude towards such a caring individual' (F14).

\section{DISCUSSION}

While the 80 Canadian medical crowdfunding campaigns we reviewed did not frame their appeals to potential donors in explicitly ethical language, the three themes we identified are associated with ethical traditions and justifications. Appeals based on personal connections with the recipient echo justifications from the ethics of care and relational ethics, where emphasis is put on the ethical demands created by concrete, intimate relationships, and especially those based on dependence. ${ }^{9}$ In the ethics of care, parenting is often used as a metaphor for the shape our ethical obligations take, based on need and relationships rather than voluntary, contractual agreements. This language was echoed in some of the reviewed campaigns, as with the campaign that appealed to potential donors in terms of a family. Relationships of dependency are emphasised in the ethics of care and were represented in these campaigns as demonstrated in the statement that donors must be there for the recipients as long as they are needed.

Campaigns that emphasised the suffering of the recipient and the good that the potential donor could achieve by giving to the campaign evoked duties of beneficence and, to some extent, utilitarian thinking. The focus on the needs of many campaign recipients was often used to make the case that the potential donor was in a position to relieve this suffering and in doing so achieve a great good, irrespective of any personal connection to the campaign's recipient. The ethical imperative created by the recipient's need and opportunity to improve their health and well-being was typically stated as a given. The particular attention given to the suffering of children is relevant in this regard as the potential to generate utility is greater among those who have the potential for longer lives. This was put explicitly in some cases, as when a campaign stated that, with the help of donors, a child recipient would live a long and happy life and in the case of even young adults for whom it was emphasised that donations were particularly worthy given their opportunity for many additional years of life.

Finally, the campaigns that appealed to potential donors based on the idea of giving back to recipients who had shown past generosity to their communities drew implicitly on the values of fairness and reciprocity. In many cases, the reader's obligation to give to the campaign was put in terms of a repayment for the past contributions of the recipient, echoing a narrow understanding of reciprocity as requiring in-kind repayments for past actions. This understanding of reciprocity can be seen in many campaigns, including those that traded on variations of the claim that it was time to 'give back'. Some campaigns deviated from a quid-pro-quo understanding of reciprocity, taking the view more generally that fairness requires that those who have given to others should receive help in their time of need. Campaigns that pledged a portion of donations to charities or research linked to the recipient's medical condition can also be read as trying to generate aid to others that should be rewarded by help for the recipient.

What is particularly notable about the justifications for contributing to medical crowdfunding campaigns identified in this analysis is that they typically did not appeal to the injustice of needing to resort to crowdfunding for care in the first place. Canada offers what it considers to be 'universal access' to essential medical care to all residents. This entitlement is widely viewed as representing a core Canadian value, that all residents should have their essential medical needs met as a matter of social justice. Failure to provide this care, either due to unavailable resources or lengthy wait times for care, have been presented as failures of the Canadian government elsewhere. ${ }^{10}$ While some of the care being sought by Canadians through crowdfunding might be considered to be non-essential, and thus not a public entitlement, many of campaigns reviewed in this study were for care that could arguably be considered to be essential. The forms of support that were requested were often not for direct medical care, which is typically provided within the public system, but for forms of social support such as hospital parking, time off work, travel expenses and other living expenses. In other cases, expenses more directly related to medical care were cited, including experimental interventions not offered within Canada or non-covered medical expenses such as for pharmaceuticals. These expenses can be described as revealing gaps in the Canada Health Act and the Canadian health system more generally. These campaigns reveal the distress faced by Canadians when they found themselves unable to meet these expenses and follow trends of increasing private expenditures related to medical care by Canadians. ${ }^{11}$

Thus, the fact that Canadians feel that they must appeal to families, friends and strangers for resources related to their medical care might reasonably be seen as an injustice-and yet, these campaigners almost exclusively chose not to frame their 
appeals for funding around the perceived injustice of their situation. A notable exception to this absence was a campaigner who described the Canadian healthcare system as a nightmare due to its failure, in her view, to appropriately diagnose her chronic Lyme disease. While this case may be an outlier, it is worth noting that those managing chronic Lyme disease are a particularly organised and politically active group, perhaps leading to their greater awareness of the perceived injustice of their situation and willingness to appeal to potential donors based on the failings of the Canadian healthcare system. ${ }^{12}$

This general absence of appeals to injustice helps to confirm what has previously been a purely speculative ethical concern with medical crowdfunding. ${ }^{5} 13$ Medical crowdfunding has the potential to mask systemic injustices in the provision of healthcare if people are able to meet their medical needs via medical crowdfunding without drawing attention to or addressing these injustices. This can be the case even if campaigners do not perceive any injustice in their situation as the language of their campaigns perpetuates a view that their need is the result more of misfortune than systemic injustice (although certainly the needs identified by crowdfunding campaigns will not always be the result of an underlying injustice). This phenomenon is particularly worrisome if there are inequities built into who succeeds with medical crowdfunding. There is good reason to think that these inequities do in face exist, as persons who have large social networks, skills with online marketing, media contacts, medical needs that are not stigmatised and the ability to express themselves in the dominant local language are likely to have more success with crowdfunding than those who lack these attributes. As a result, medical crowdfunding can increase health inequities while making it more difficult to observe and counteract systemic injustice. The almost universal indifference to issues of justice observed in this study highlight that this concern is well founded and should be addressed.

\section{CONCLUSION}

This study demonstrated that Canadians using crowdfunding websites to raise money for medical care appeal to personal connections, the capacity of donors to relieve their suffering and giving back to those who have given to others in order to encourage donations. These types of appeals can be linked to ethical justifications found in the ethics of care, a duty of beneficence or utilitarian ethics and the values of reciprocity and fairness, respectively. These campaigns almost universally did not appeal to the perceived injustice of having to resort to crowdfunding by Canadians with an existing entitlement to essential medical care, supporting the concern that medical crowdfunding can obscure systemic injustices and widen health inequities.
These findings support the need for additional research linked to ethical issues raised by medical crowdfunding. Additional research should investigate whether any of the appeals observed here are more successful than others in motivating giving and whether these appeals are observed in populations outside of Canada. Qualitative interviews with crowdfunding campaigners could also explore whether they perceived but did not appeal to injustice when initiating their campaigns and, if so, why.

Contributors All authors made substantial contributions to the conception or design of the work and analysis of data for the work. All authors contributed to drafting the work or revising it critically for important intellectual content, gave final approval of the version to be published and agreed to be accountable for all aspects of the work in ensuring that questions related to the accuracy or integrity of any part of the work are appropriately investigated and resolved.

Funding Michael Smith Foundation for Health Research, Canadian Institutes of Health Research.

Competing interests None declared.

Provenance and peer review Not commissioned; externally peer reviewed.

Open Access This is an Open Access article distributed in accordance with the Creative Commons Attribution Non Commercial (CC BY-NC 4.0) license, which permits others to distribute, remix, adapt, build upon this work non-commercially, and license their derivative works on different terms, provided the original work is properly cited and the use is non-commercial. See: http://creativecommons.org/ licenses/by-nc/4.0/

\section{REFERENCES}

1 Gustke C. Managing health costs with crowdfunding. New York Times, 30 January 2015.

2 Romm C. Is it fair to ask the internet to pay your hospital bill? The Atlantic, 12 March 2015

3 Chandler R. GoFundMe sees boom in medically-related fundraising campaigns. WHO TV March 14, 2015.

4 Sisler J. Crowdfunding for medical expenses. CMAJ 2012;184.2:E123-4.

5 Snyder J. Crowdfunding for medical care: ethical issues in an emerging health care funding practice. Hastings Cent Rep 2016;46:36-42.

6 Herzenstein M, Sonenshein S, Dholakia UM. Tell me a good story and I may lend you money: the role of narratives in peer-to-peer lending decisions. J Mark Res 2011;48(SPL):S138-49.

7 Gleasure R, Feller J. Does heart or head rule donor behaviors in charitable crowdfunding markets? Int J Electron Commerce 2016;20:499-524.

8 Creswell JW. Research design: qualitative, quantitative and mixed methods approaches. 3rd edn. Thousand Oaks, CA: Sage, 2009.

9 Kittay EF. Love's labor: essays on women, equality, and dependency. New York, NY Routledge, 1999.

10 Romanow RJ. Shape the future of health care: interim report. Saskatoon, SK: The Commission, 2002.

11 Law MR, Daw JR, Cheng L, et al. Growth in private payments for health care by Canadian households. Health Policy 2013;110:141-6.

12 McPhail M, Shelley J. The role of patient advocates in Lyme disease policy should be limited. Healthy Debate 15 June 2016.

13 Snyder J, Mathers A, Crooks VA. Fund my treatment! A call for ethics-focused social science research into the use of crowdfunding for medical care. Soc Sci Med 2016;169:27-30. 